\title{
Observed and simulated trophic index (TRIX) values for the Adriatic Sea basin
}

\author{
Emanuela Fiori $^{1,2,3}$, Marco Zavatarelli ${ }^{1,2}$, Nadia Pinardi ${ }^{1,4}$, Cristina Mazziotti $^{3}$, and Carla Rita Ferrari ${ }^{3}$ \\ ${ }^{1}$ Dipartimento di Fisica e Astronomia (DIFA) University of Bologna, Viale Berti Pichat, 6/2, 40127 Bologna, Italy \\ ${ }^{2}$ Consorzio Nazionale Interuniversitario per le Scienze dal Mare, Piazzale Flaminio 9, 00195 Rome, Italy \\ ${ }^{3}$ Agenzia Regionale Prevenzione Ambiente Energia (ARPAE) dell'Emilia-Romagna, Struttura Oceanografica Daphne, \\ Viale Vespucci, 2, 47042 Cesenatico (FC), Italy \\ ${ }^{4}$ Centro EuroMediterraneo sui Cambiamenti Climatici, Lecce, Italy
}

Correspondence to: Emanuela Fiori (e.fiori@sincem.unibo.it)

Received: 2 March 2016 - Published in Nat. Hazards Earth Syst. Sci. Discuss.: 9 March 2016

Revised: 9 August 2016 - Accepted: 11 August 2016 - Published: 2 September 2016

\begin{abstract}
The main scope of the Marine Strategy Framework Directive is to achieve good environmental status (GES) of the EU's marine waters by 2020 , in order to protect the marine environment more effectively. The trophic index (TRIX) was developed by Vollenweider in 1998 for the coastal area of Emilia-Romagna (northern Adriatic Sea) and was used by the Italian legislation to characterize the trophic state of coastal waters.

We compared the TRIX index calculated from in situ data ("in situ TRIX") with the corresponding index simulated with a coupled physics and biogeochemical numerical model ("model TRIX") implemented in the overall Adriatic Sea. The comparison between in situ and simulated data was carried out for a data time series on the Emilia-Romagna coastal strip. This study shows the compatibility of the model with the in situ TRIX and the importance of the length of the time series in order to get robust index estimates. The model TRIX is finally calculated for the whole Adriatic Sea, showing trophic index differences across the Adriatic coastal areas.
\end{abstract}

\section{Introduction}

Marine habitats are subject to increasing pressures (as nutrient discharges, eutrophication) due to agriculture, industry, tourism, fishing, and aquaculture. The eutrophication of coastal waters is considered to be one of the greatest threats to the health of marine ecosystems. It is described as a change in the marine food web connected to the seawater enrichment by nutrients, which can modify the carbon pathways and excessive oxygen consumption (Ferreira et al., 2011; Vollenweider et al., 1992).

In response to these pressures, the Marine Strategy Framework Directive (MSFD, 2008/56/EC) explicitly considers eutrophication descriptors as key to determining the good environmental status (GES) of European coastal waters. The EU MSFD addresses the overall state of the marine environment utilizing a DPSIR (driver, pressure, state, impact, response) conceptual approach and considering eutrophication as an important process that can alter the coastal waters' GES. A synthetic indicator of the environmental state of the coastal ocean with respect to the eutrophication processes, integrating elements of the DPSIR methodology, is therefore very useful to provide an objective assessment of the environmental state. Furthermore, it provides elements for the implementation of an ecosystem-based strategy for the achievement and maintenance of GES. The MSFD underlines the need to implement an ecosystem-based approach to determine all the pressures affecting the marine environment relative to GES. Indicators therefore need to be developed to qualitatively and quantitatively assess the quality of the marine environment. Marine ecosystems present high levels of complexity; hence composite indicators are needed to support monitoring programs and reduce complexity for early-warning systems.

Eutrophication assessment indicators should use multivariate water column state variables, integrating physicalchemical and biological variables. The trophic index (TRIX) 
is a eutrophication index proposed by Vollenweider et al. (1998) in order to characterize the trophic state of marine waters along the Emilia-Romagna coastal region (northwestern Adriatic Sea). TRIX is defined by four state variables, which are strongly correlated with primary production: chlorophyll $a$, oxygen, dissolved inorganic nitrogen, and total phosphorous. TRIX was integrated into Italian law for the monitoring of the coastal marine environment status (D.L. 260/2010, Table 4.3.2/c).

TRIX covers a wide range of trophic conditions from oligotrophy to eutrophy, and it has been applied to coastal marine waters in several European seas: the Adriatic Sea and the Tyrrhenian Sea (Giovanardi and Vollenweider, 2004), the Black Sea (Kovalova and Medinets, 2012; Baytut, 2010; Dyatlov et al., 2010; Medinets et al., 2010; Moncheva and Doncheva, 2000; Moncheva et al., 2002; Zaika, 2003), the eastern Mediterranean Sea (Tugrul et al., 2011), the Aegean Sea (Yucel-Gier et al., 2011), the Marmara Sea (Balkis et al., 2012), the Caspian Sea (Shahrban and Etemad-Shahidi, 2010), the Mar Menor (Salas et al., 2008), the Persian Gulf (Zoriasatein et al., 2013), and the Gulf of Finland (Vaschetta et al., 2008).

In this paper we compare "in situ TRIX" with model simulations for long data series in different coastal and openocean areas. The specific objectives of our work are (1) to adapt the TRIX generic relation to numerical ecosystem model simulation data, (2) to validate the "model TRIX" with in situ data in different areas and time series, and (3) to apply the TRIX generic equation to other coastal and open-ocean areas in the entire Adriatic Sea.

The final results of this paper could be used as a criterion to classify the marine ecosystem (D.L. 260/2010), providing class boundaries expressed as TRIX units (Table 4.3.2./c). Furthermore, it is shown that the ecosystem simulations can represent an important support for monitoring activities, allowing TRIX to be extended to larger areas where in situ sampling activities are difficult to implement.

Section 2 describes the TRIX equation and its calibration parameters for the model simulations. Section 3 illustrates the in situ and simulation model data used for the evaluation of TRIX and its calibration. Section 4 compares the in situ TRIX and model TRIX, and the sensitivity analysis of the calibration parameters. Section 5 shows how TRIX could be implemented for the whole Adriatic Sea region, and Sect. 6 presents the discussion and conclusions.

\section{TRIX equation and parameterizations}

The TRIX index was developed by Vollenweider et al. (1992) using data collected between 1982 and 1993 by the "Daphne" oceanographic division of the Emilia-Romagna Regional Environmental Protection Agency (hereafter referred to as ARPAE-Daphne). Since 1971 ARPAE-Daphne has been carrying out a monitoring program (Regione Emilia-Romagna,

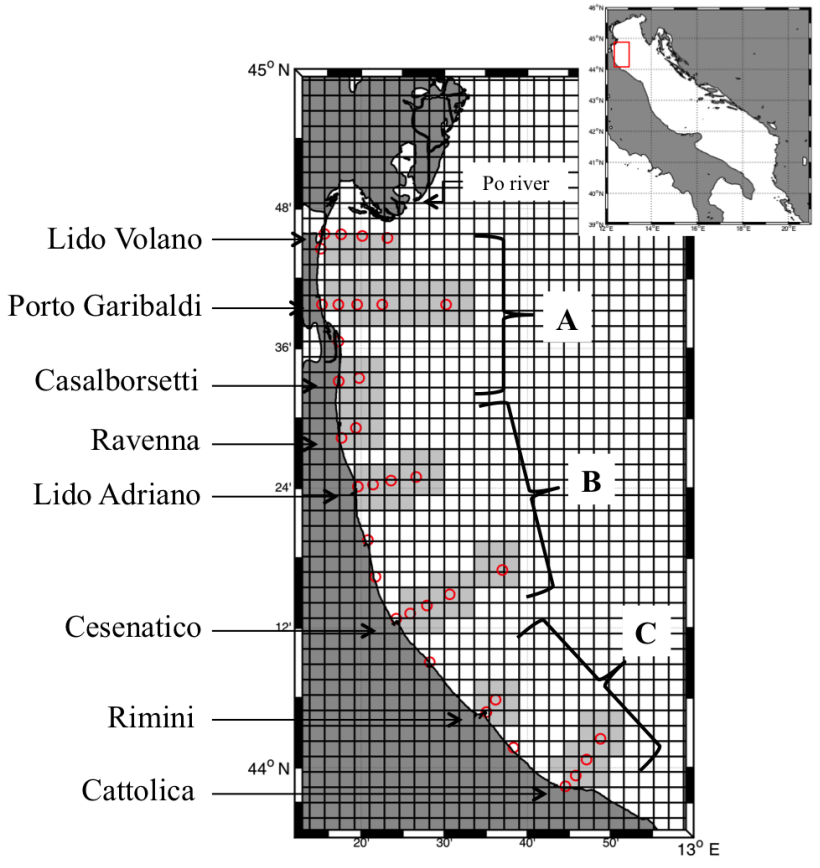

Figure 1. Emilia-Romagna coastal and shelf region monitored by ARPAE-Daphne: 21 stations, organized along eight transects (Lido Volano, Porto Garibaldi, Casalborsetti, Ravenna, Lido Adriano, Cesenatico, Rimini, and Cattolica) from $500 \mathrm{~m}$ to $10 \mathrm{~km}$ distance from the coast. The Porto Garibaldi and Cesenatico transects enclose also two stations situated $20 \mathrm{~km}$ offshore. The study area is divided into three areas (A, B, and C) based on hydrological and trophic conditions. The grey shaded areas indicate the model grid points from which model data were extracted to carry out the model TRIX.

1981-2013) covering the whole of the Emilia-Romagna coastal region. The location of the sampling stations is reported in Fig. 1.

The TRIX index is based on four state variables $(n)$, which are directly related to productivity: chlorophyll $a$ $\left(\mathrm{Chl}, \mathrm{mg} \mathrm{m}^{-3}\right.$ ), oxygen as the absolute percentage deviation from oxygen saturation (DO, \%), dissolved inorganic nitrogen (DIN, $\mathrm{mg} \mathrm{m}^{-3}$ ), and total phosphorous (TP, $\mathrm{mg} \mathrm{m}^{-3}$ ). In particular, $\mathrm{DIN}=\mathrm{N}-\mathrm{NO}_{3}+\mathrm{N}-\mathrm{NO}_{2}+\mathrm{N}-\mathrm{NH}_{4}$ and $\mathrm{DO}=$ $\left|100-\mathrm{O}_{x}\right|$, where $\mathrm{O}_{x}$ is the oxygen saturation. Each state variable is scaled by the highest $\left(U_{i}\right)$ and the lowest $\left(L_{i}\right)$ values in the data time series, and TRIX is defined as

TRIX $=\frac{k}{n} \sum_{i=1}^{n} \frac{\left(\log M_{i}-\log L_{i}\right)}{\left(\log U_{i}-\log L_{i}\right)}$,

where $k=10$ is another scaling factor; $n$ is the number of state variables considered; and $M_{i}$ are the observed Chl, DO, DIN, and TP values.

Vollenweider et al. (1998) further simplified the TRIX formula by assuming (on the basis of the data used) that the difference $\left(\log U_{i}-\log L_{i}\right)$ was equal to 3 for all state variables. Therefore, considering $k=10, n=4$, and the specific $\log L_{i}$ 
Table 1. Reference values of the trophic index (TRIX) and corresponding water quality and trophic conditions, developed from ARPAEDaphne Emilia-Romagna (Rinaldi and Giovanardi, 2011).

\begin{tabular}{|c|c|c|c|}
\hline Conditions & TRIX units & Trophic state & Water quality conditions \\
\hline \multirow[t]{3}{*}{ Oligotrophic } & $<4$ & Elevated & $\begin{array}{l}\text { - Scarcely productive waters } \\
\text { - Good water transparency } \\
\text { - Absence of anomalous water colors } \\
\text { - Absence of oxygen undersaturation in the bottom waters }\end{array}$ \\
\hline & $4 \ll 5$ & Good & $\begin{array}{l}\text { - Moderately productive waters } \\
\text { - Occasionally water turbidity } \\
\text { - Occasionally anomalous water colors } \\
\text { - Occasionally bottom waters hypoxia episodes }\end{array}$ \\
\hline & $5 \ll 6$ & Mediocre & $\begin{array}{l}\text { - Very productive waters } \\
\text { - Low water transparency } \\
\text { - Frequently anomalous waters colors } \\
\text { - Hypoxia and occasionally anoxia episodes in the bottom layers } \\
\text { - Suffering of the benthic communities }\end{array}$ \\
\hline Eutrophic & $>6$ & $\mathrm{Bad}$ & $\begin{array}{l}\text { - Strongly productive waters } \\
\text { - High water turbidity } \\
\text { - Diffuse and persistent anomaly in the water colors } \\
\text { - Diffuse and persistent hypoxia/anoxia episodes in the bottom waters } \\
\text { - High mortality rate of benthic organisms } \\
\text { - Alteration of the benthic communities and strong decrease of the biodiversity }\end{array}$ \\
\hline
\end{tabular}

values (see Table III in Vollenweider et al., 1998), the TRIX formula was rewritten as follows:

$$
\begin{aligned}
\text { TRIX }= & \frac{10}{12}\left[\left(\log M_{\mathrm{chl}}+0.5\right)+\left(\log M_{\mathrm{DO}}+1\right)\right. \\
& \left.+\left(\log M_{\mathrm{DIN}}-0.5\right)+\left(\log M_{\mathrm{TP}}+0.5\right)\right]
\end{aligned}
$$

or

$$
\text { TRIX }=\frac{1}{1.2}\left[\log \left(M_{\mathrm{chl}} M_{\mathrm{DO}} M_{\mathrm{DIN}} M_{\mathrm{TP}}\right)+1.5\right]
$$

Equation (2) gives the TRIX index currently used by ARPAE-Daphne and adopted by the Italian national legislation (D.L. 260/2010). For the Italian coastal waters, TRIX values range from 0 to 10: 0 corresponds to extreme oligotrophic conditions; while10 corresponds to extreme eutrophic conditions. TRIX values have been further aggregated into four trophic regimes (Rinaldi and Giovanardi, 2011): "elevated", "good", "mediocre", and "bad" (Table 1). Referring to Italian waters, TRIX values exceeding 6 are typical of highly productive coastal areas, characterized by frequent episodes of sea bottom anoxia (Giovanardi and Vollenweider, 2004).

In the following sections we calculate the TRIX index scaling parameters $U_{i}$ and $L_{i}$ on the basis of different (observed and simulated) data sets, in order to evaluate the possibility of applying the TRIX to numerical simulation data and extending the calculation to open-ocean areas. The assessment is carried out by closely comparing the simulated TRIX (model TRIX) with corresponding values from in situ observations (in situ TRIX).
In addition to TRIX, an efficiency coefficient can also be defined (Giovanardi and Vollenweider, 2004) as the logarithm of the ratio between the two aggregated main components of the TRIX, i.e.,

eff. coeff. $=\log \left(\frac{\mathrm{Chl} \times \mathrm{DO}}{\mathrm{DIN} \times \mathrm{TP}}\right)$.

The efficiency coefficient can be considered a supplementary index with which to evaluate the nutrient utilization of the system. In the present study we also calculate the efficiency coefficient from both in situ data and model simulations.

\section{In situ and model data}

\subsection{In situ data}

The in situ data used in this paper were collected by the ARPAE-Daphne monitoring program. We considered the 1982-1993 data time series originally used by Vollenweider et al. (1998) to calibrate in situ TRIX and an additional recent time series covering the period 2001-2012 to validate the model TRIX. The monitoring grid considers 21 sampling stations located along eight transects perpendicular to the coast: 19 stations are coastal, extending from $500 \mathrm{~m}$ to $10 \mathrm{~km}$ offshore, while two stations are at a $20 \mathrm{~km}$ distance, sampling an open shelf regime. All the stations are monitored weekly. ARPAE-Daphne divided the monitored area into three subareas (area A, B, and C in Fig. 1) on the basis of the hy- 
Table 2. Lower $\left(L_{i}\right)$, upper $\left(U_{i}\right)$, and difference $\left(\log U_{i}-\log L_{i}\right)$ logarithm value of the four state variables considered by the TRIX index. Values are extracted from the simulated data series reported in the first column.

\begin{tabular}{|c|c|c|c|c|c|}
\hline Time series & Limits & Chl & DIN & $\mathrm{TP}$ & DO \\
\hline \multirow[t]{3}{*}{ 1982-1993 } & $\log L_{i}$ & -0.72 & 1.15 & 0.07 & -4.16 \\
\hline & $\log U_{i}$ & 1.12 & 3.22 & 2.77 & 1.96 \\
\hline & $\log U_{i}-\log L_{i}$ & 1.84 & 2.06 & 2.70 & 6.12 \\
\hline \multirow[t]{3}{*}{ 1991-2010 } & $\log L_{i}$ & -0.99 & 1.84 & -0.20 & -5.01 \\
\hline & $\log U_{i}$ & 1.02 & 3.29 & 2.54 & 1.84 \\
\hline & $\log U_{i}-\log L_{i}$ & 2.01 & 1.45 & 2.74 & 6.85 \\
\hline \multirow[t]{3}{*}{$2001-2010$} & $\log L_{i}$ & -0.99 & 1.84 & -0.20 & 0.001 \\
\hline & $\log U_{i}$ & 0.79 & 3.13 & 2.36 & 1.84 \\
\hline & $\log U_{i}-\log L_{i}$ & 1.79 & 1.29 & 2.56 & 4.82 \\
\hline \multirow[t]{3}{*}{ 2006-2010 } & $\log L_{i}$ & -0.98 & 1.84 & -0.20 & -2.84 \\
\hline & $\log U_{i}$ & 0.79 & 3.11 & 2.36 & 1.84 \\
\hline & $\log U_{i}-\log L_{i}$ & 1.77 & 1.27 & 2.56 & 4.68 \\
\hline
\end{tabular}

drological and trophic conditions (Montanari et al., 2006). Area A is located immediately south of the Po delta and is directly affected by river runoff and nutrient load (see Po River in Fig. 1); it is therefore characterized by enhanced primary production. Area $\mathrm{B}$ is a transition area, while area $\mathrm{C}$ is characterized by hydrographical conditions mainly governed by the large-scale basin circulation.

The in situ TRIX was calculated for each station (using surface values of Chl, DO, DIN, and TP) and averaged over the eight transects and the three subareas. At the Porto Garibaldi and Cesenatico transects (see Fig. 1), TRIX was calculated with and without the open-shelf stations.

\subsection{Numerical model data}

The model data used in this study were produced by the three-dimensional coupled circulation-biogeochemical model consisting of the Princeton Ocean Model (POM; Blumberg and Mellor, 1987) and the Biogeochemical Flux Model (BFM; Vichi et al., 2007). The model was implemented in the Adriatic Sea at a horizontal resolution of about $2 \mathrm{~km}$, and 27 sigma layers defined the vertical resolution (Clementi et al., 2010).

BFM is a complex lower trophic marine biogeochemical model. It is a biomass-based model, designed to simulate the main marine biogeochemical fluxes through a description of the ecological functions of the producers, decomposers, and consumers and their specific trophic interactions in terms of basic elements (carbon, nitrogen, phosphorous, silicon, and oxygen) flows. The biological constituents of the model are organized into chemical functional families (CFFs) and living functional groups (LFGs). CFFs are divided into organic (living and non-living) and inorganic compounds, which are measured in equivalents of major chemical elements or in molecular weight units. BFM receives information from the
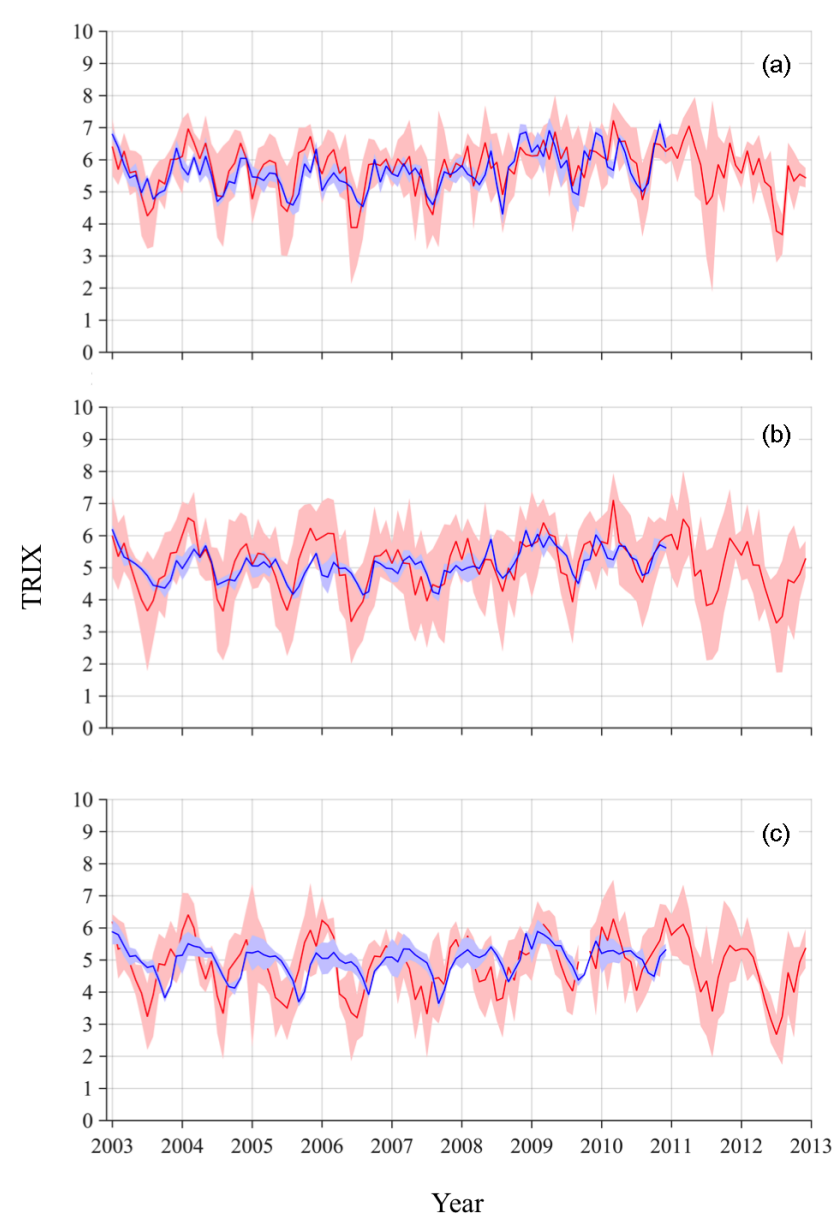

Figure 2. Comparison between in situ TRIX (red line) and model TRIX (blue line) averaged over the three study areas (A, B, and C). Model TRIX was calculated using $U_{i}$ and $L_{i}$ values extracted from the numerical simulations relative to the period 1982-1993. Red and blue shaded areas correspond to average values \pm 2 standard deviations.

hydrodynamic model regarding temperature and salinity in order to calculate oxygen saturation.

The simulations were carried out for the period 19802010. Nutrients, oxygen, and chlorophyll values were extracted at the model grid points nearest to the in situ sampling stations (grey shaded areas in Fig. 1). The model TRIX was then defined with $U_{i}$ and $L_{i}$ values computed using different time periods (Eq. 1): 1982-1993 (model TRIX), 1991-2010 ("model TRIX 1"), 2001-2010 ("model TRIX 2") and 20062010 ("model TRIX 3"). The values obtained are reported in Table 2, and the model TRIX values estimated from these different scaling parameters were compared with in situ values. 
Table 3. Pearson's correlation values between in situ TRIX and the TRIX calculated from model simulations $(p$ value $<0.01$ for all the periods and areas). For model TRIX $U_{i}$ and $L_{i}$ values from different time series were considered: 1982-1993 (model TRIX), 1991-2010 (model TRIX 1), 2001-2010 (model TRIX 2), 2006-2010 (model TRIX 3). For each study area the number of in situ data ( $N$ ) is listed.

\begin{tabular}{|c|c|c|c|c|c|}
\hline Area & $N$ & $\begin{array}{c}\text { Correlation } \\
\text { (model TRIX with } \\
\text { 1982-1993 coefficients) }\end{array}$ & $\begin{array}{c}\text { Correlation } \\
\text { (model TRIX with } \\
\text { 1991-2010 coefficients) }\end{array}$ & $\begin{array}{c}\text { Correlation } \\
\text { (model TRIX with } \\
\text { 2001-2010 coefficients) }\end{array}$ & $\begin{array}{c}\text { Correlation } \\
\text { (model TRIX with } \\
\text { 2006-2010 coefficients) }\end{array}$ \\
\hline A & 2089 & 0.64 & 0.64 & 0.63 & 0.63 \\
\hline B & 2104 & 0.58 & 0.57 & 0.53 & 0.53 \\
\hline $\mathrm{C}$ & 1048 & 0.36 & 0.36 & 0.31 & 0.30 \\
\hline
\end{tabular}

\section{Comparison of TRIX estimates from in situ and simulated data}

Figure 2 shows the comparison of the in situ and model TRIX considering the upper $\left(U_{i}\right)$ and lower $\left(L_{i}\right)$ values of each state variable obtained from the observed and simulated 19831992 time series respectively. The figure clearly shows that the model TRIX lies in the same range of the in situ TRIX and the two time series show a distinct seasonal cycle with some degree of similarity. We computed the Pearson correlation coefficient using the simulated and the observed data series for the three subareas of the monitored region and we found that the $p$ value are always lower than 0.01 for all regions and normalization values. The correlation coefficient values are reported in Table 3 and they show decreasing values from area $\mathrm{A}$ to $\mathrm{C}$.

Area A has the highest correlation values since it is the most eutrophic area, exhibiting the highest TRIX values (>6), depending on the direct influence of the freshwater runoff and nutrient load from the Po River delta (Fig. 1) immediately northward of area A. Areas B and C show progressively reduced TRIX values (Fig. $2 b$ and c), denoting more oligotrophic conditions and reduced correlation values. This is mostly due to a slight model underestimation of the index in area B between 2003 and 2006. Area C shows the lowest correlation because there is a temporal phase shift (of about 2 months) between the two time series between 2005 and 2008. We presume that this is due to the particular Po River runoff and climatic conditions that are not well reproduced by the model.

In all the three study areas, TRIX increases between 2008 and 2010. Area A shows values above 6 (bad water quality conditions; see Table 1) in late winter-early spring and late summer-early autumn (Fig. 2). Areas B and C are characterized by TRIX values that indicate mediocre $(5<$ TRIX $<6$ in winter-spring) to good ( $4<$ TRIX $<5$ in summer-autumn) conditions. However, some high in situ TRIX events $(>6)$ were recorded also in Area B during spring 2004 and 2010, while the model TRIX simulates values below 6 for all the periods.

The percentage contribution of each variable (Chl, DO, DIN, and TP) to the TRIX index as a function of time was calculated in the three subareas for in situ data and model

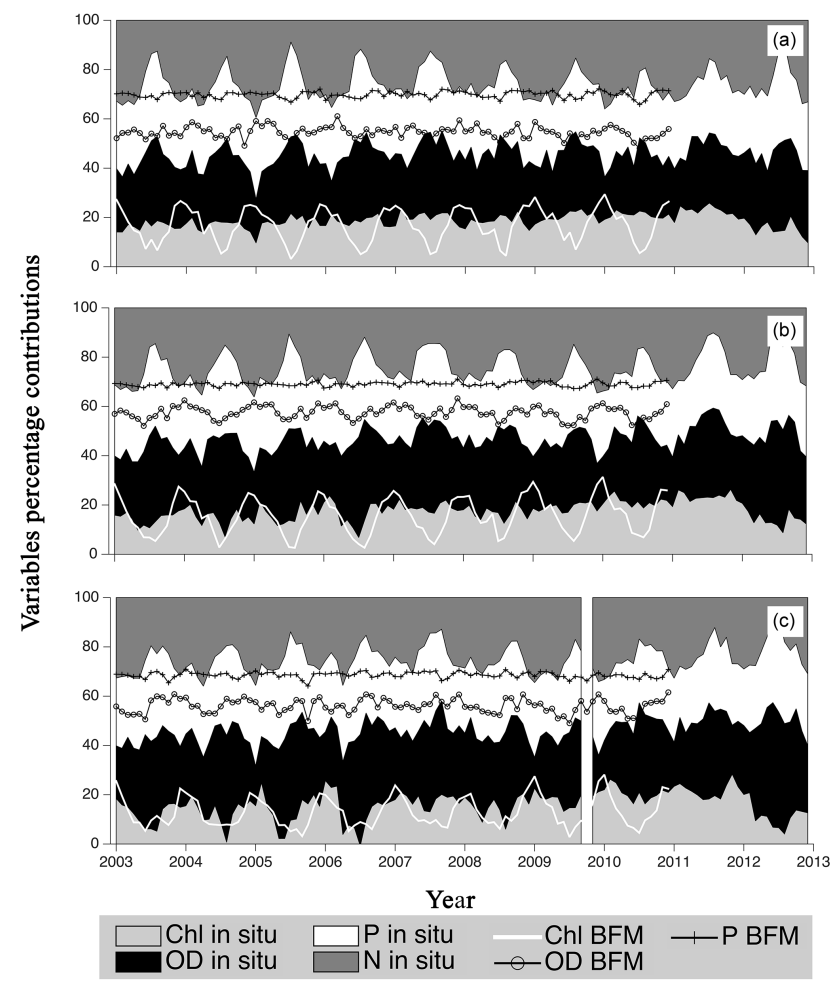

Figure 3. Percentage contributions of the four variables (Chl, DO, DIN, and TP) calculated as in Eq. (4) to the in situ TRIX (colored areas) and the model TRIX index (continuous lines with different symbols) in the three study areas (A, B, and C).

simulations (Fig. 3). The percentage is defined as

$P_{i}=100 \frac{\frac{\left(\log M_{i}-\log L_{i}\right)}{\left(\log U_{i}-\log L_{i}\right)}}{\sum_{i=1}^{n} \frac{\left(\log M_{i}-\log L_{i}\right)}{\left(\log U_{i}-\log L_{i}\right)}}$,

where $M_{i}$ are the observed values of the four basic variables - Chl, DO, DIN, and TP - while $U_{i}$ and $L_{i}$ represent the highest and the lowest values of each variables in the data time series, respectively.

The model generally overestimates the dissolved oxygen. The mean DO percentage contribution calculated from model simulations corresponds to $40.86 \%$, while the DO 

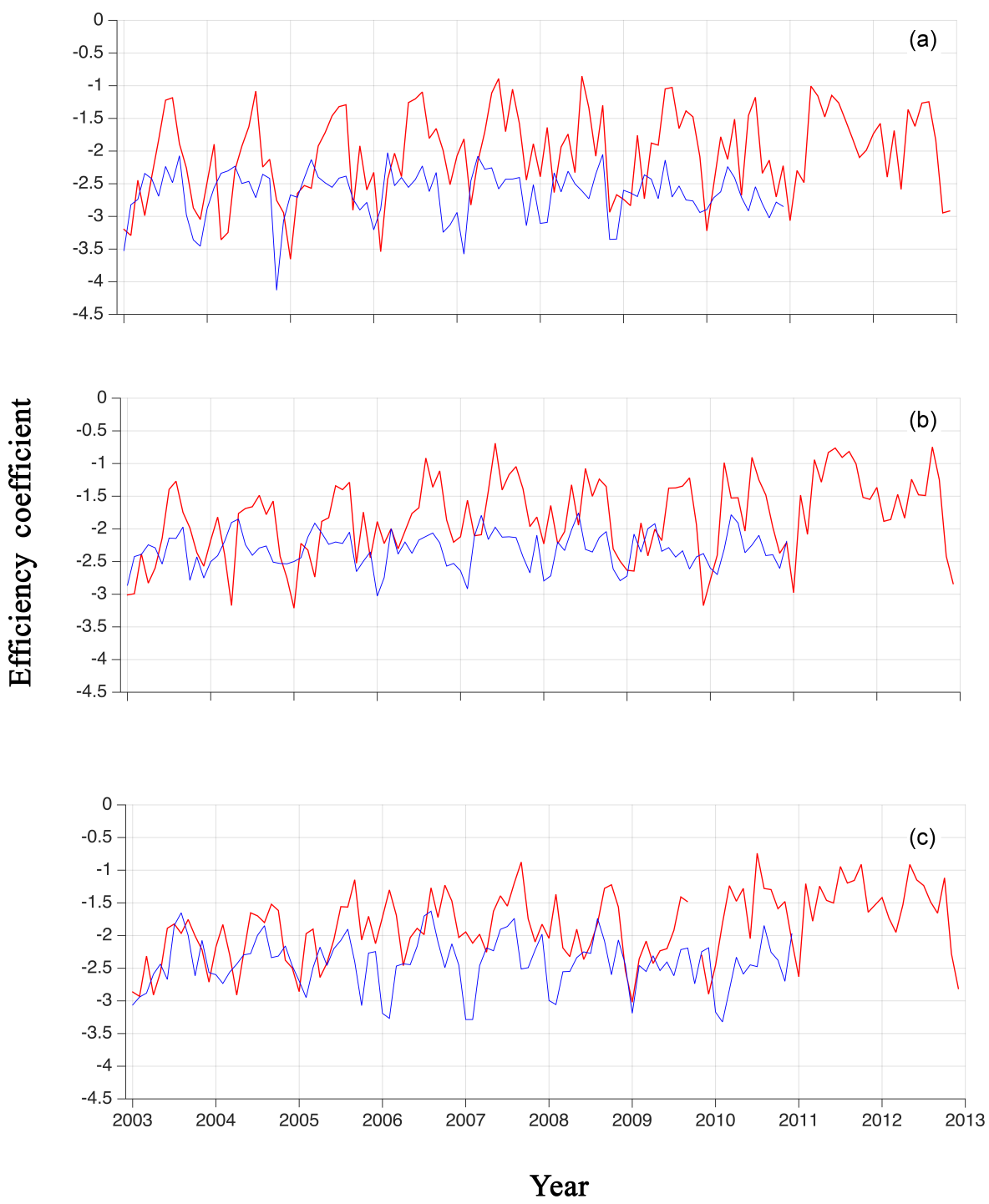

- In situ-Simulated

Figure 4. Efficiency coefficient calculated from in situ data (red line) and model simulations (blue line) in the three study areas (A, B, and C).

percentage contribution calculated from in situ data corresponds to $28.86 \%$. However, the percentage contribution of the simulated total phosphorous is generally lower (mean value: $13.10 \%$ ) compared to the in situ data (mean value: $28.55 \%$ ). The percentage contributions of the simulated chlorophyll (mean value: $15.21 \%$ ) and dissolved inorganic nitrogen (mean value: $30.82 \%$ ) were in the same range as the in situ data (mean values: 17.37 and $25.21 \%$ for chlorophyll and inorganic nitrogen, respectively). This means that the estimated model TRIX reaches similar values (Fig. 2) to the in situ ones for different reasons, which can be explained by the efficiency coefficient.

The efficiency coefficient calculated from in situ data range between -3.5 and -0.5 (Fig. 4), while the model tends to underestimate this parameter in all the areas (ranging between -4 and -1.5 ). This means that the model simulates an ecosystem which is slightly less efficient than the natural one to convert nutrients into primary producers biomass and by consequence the oxygen levels remain higher than in the natural case. In addition it is also clear that the model underestimates the seasonal variability of the PO and DIN percentages generating a smaller amplitude seasonal cycle in the efficiency coefficient (Fig. 4).

The TRIX index calculated as averages of each monitoring transect (Lido Volano, Casalborsetti, Ravenna, Lido Adriano, Rimini, Cattolica, Porto Garibaldi, and Cesenatico, in Fig. 1) instead of averages over the areas A, B, and C provides indications that are consistent with the previous results (see 
Table 4. Pearson's correlation values between the in situ TRIX and the model TRIX ( $p$ value $<0.01$ for all transects). All the transects are comprised of coastal stations (up to $10 \mathrm{~km}$ distance from the coast, Fig. 1), while two transect (Porto Garibaldi and Cesenatico, Fig. 1) contained offshore stations (at $20 \mathrm{~km}$ distance from the coast). The number of records $(N)$ available for each transect is listed.

\begin{tabular}{lcccc}
\hline Transect & $N$ & $\begin{array}{c}\text { Coastal stations' } \\
\text { correlation coefficient }\end{array}$ & $N$ & $\begin{array}{c}\text { Offshore stations' } \\
\text { correlation coefficient }\end{array}$ \\
\hline Lido Volano & 773 & 0.63 & - & - \\
Porto Garibaldi & 788 & 0.72 & 906 & 0.63 \\
Casalborsetti & 528 & 0.70 & - & - \\
Ravenna & 496 & 0.72 & - & - \\
Lido Adriano & 784 & 0.58 & - & - \\
Cesenatico & 824 & 0.48 & 923 & 0.48 \\
Rimini & 267 & 0.36 & - & - \\
Cattolica & 781 & 0.34 & - & - \\
\hline
\end{tabular}
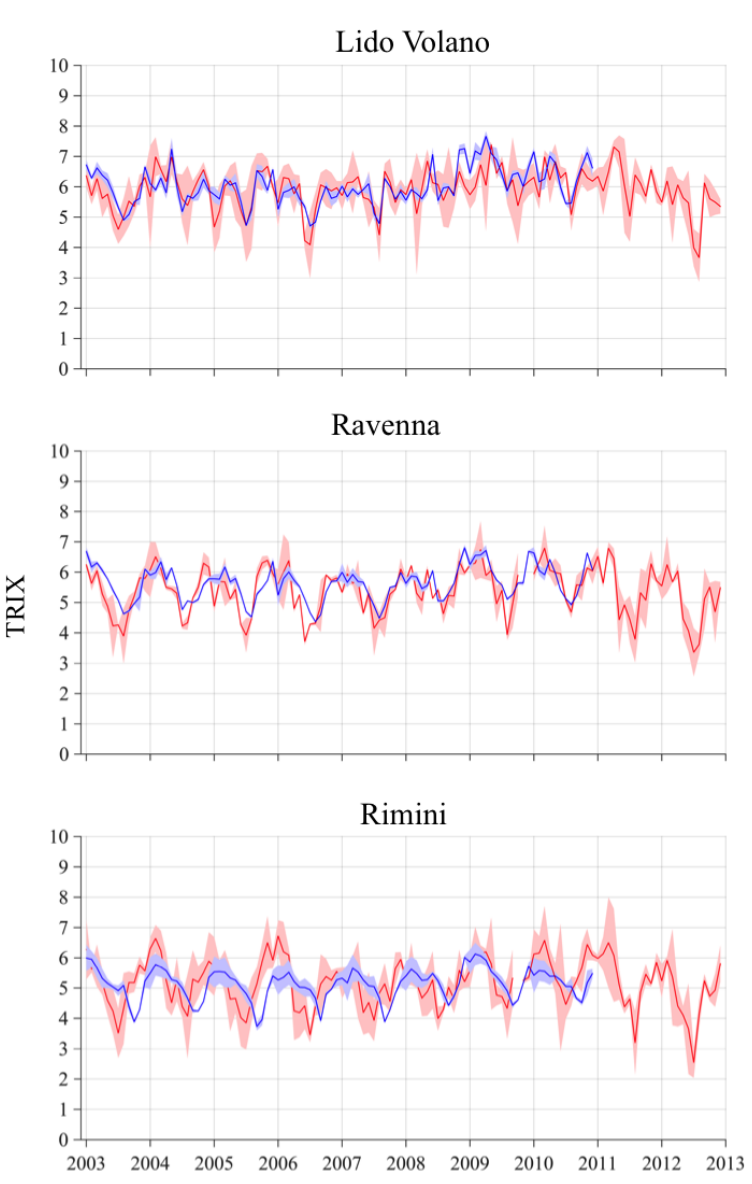
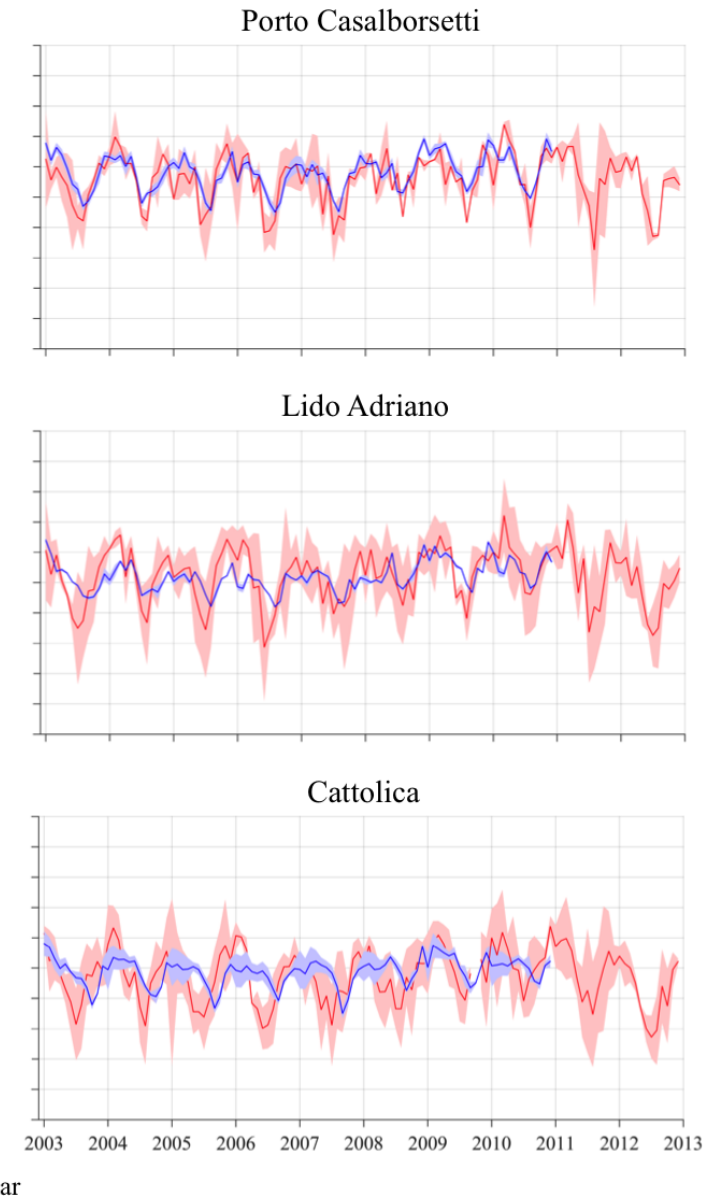

Figure 5. Comparison between in situ TRIX (red line) and model TRIX (blue line) averaged over six transects (Lido Volano, Casalborsetti, Ravenna, Lido Adriano, Rimini, and Cattolica) comprising the ARPAE-Daphne monitoring sampling program. Red and blue shaded areas correspond to average values \pm 2 standard deviations.

Fig. 5). The Pearson correlation values relative to each transect are reported in Table 4 for all the transects (the $p$ value is always lower than 0.01 , so that all correlation values are statistically different from 0 ). The correlation values again highlight that the overall qualitative agreement between model and in situ TRIX is reduced moving along a eutrophy-tooligotrophy (north-to-south) gradient.

A preliminary conclusion is that model TRIX agrees, within the 2-standard-deviation range, with the corresponding in situ index. In addition the model TRIX estimates ap- 

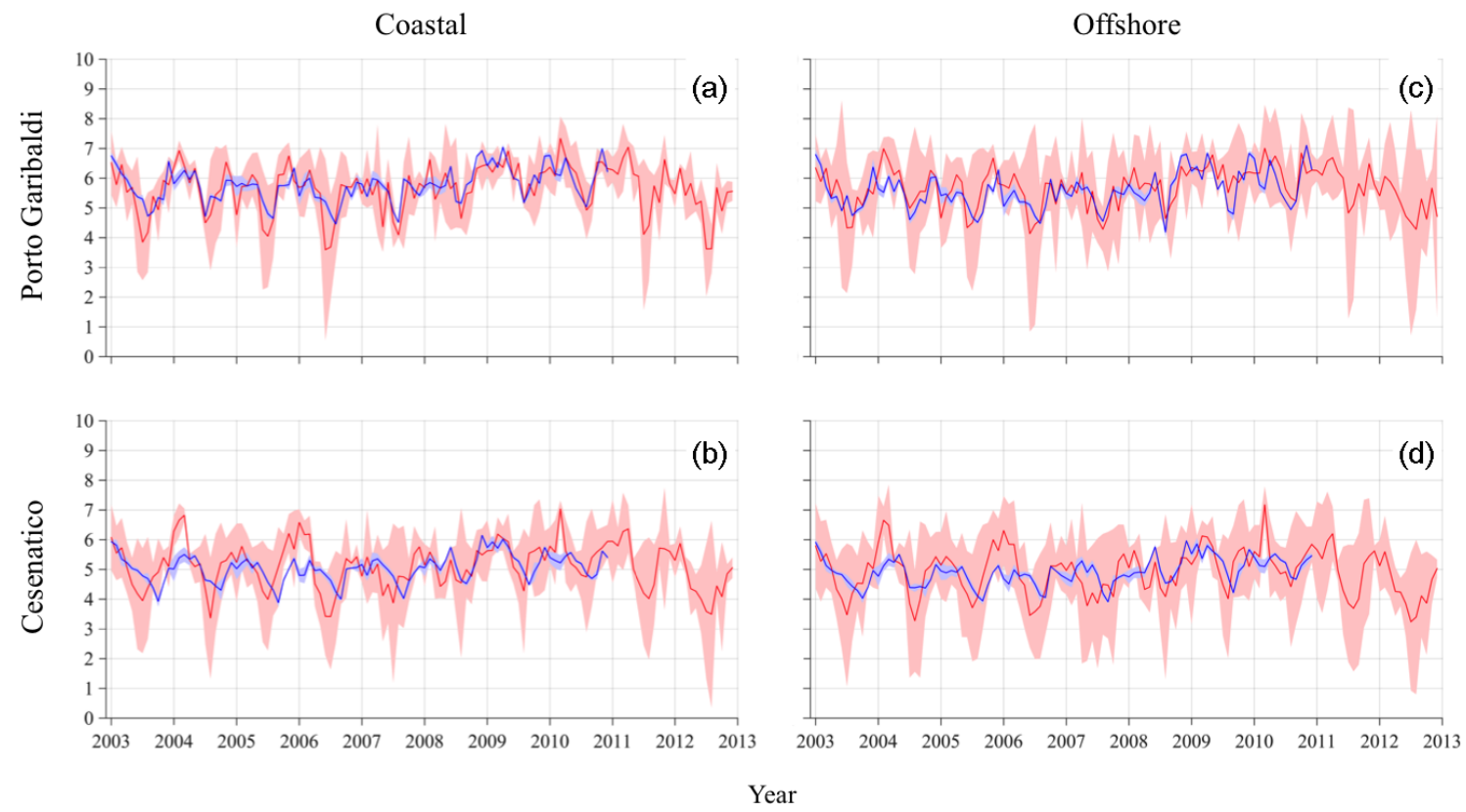

Figure 6. Comparison between in situ TRIX (red line) and model TRIX (blue line) averaged over two transects (Porto Garibaldi and Cesenatico), including stations up to $10 \mathrm{~km}$ distance from the coast (coastal, $\mathbf{a}$ and $\mathbf{b}$ ) and up to $20 \mathrm{~km}$ distance from the coast (offshore, $\mathbf{c}$ and $\mathbf{d}$ ). Red and blue shaded areas correspond to average values \pm 2 standard deviations.

pear more coherent with in situ estimations for trophic conditions characterized by a tendency towards eutrophy.

\subsection{Model TRIX sensitivity analysis}

A sensitivity analysis was carried out by comparing the TRIX index calculated only with the coastal stations, up to $10 \mathrm{~km}$ distance from the coast (Fig. 6a and b), and the TRIX index computed also considering the two offshore stations, situated at $20 \mathrm{~km}$ off the coast for the Porto Garibaldi and Cesenatico transects (Fig. $6 \mathrm{c}$ and d). The Pearson correlation coefficient decreased for the Porto Garibaldi transect and did not change for the Cesenatico transect (Table 4), but all $p$ values are lower than 0.01 ; that means they are statistically significant. This further confirms that TRIX is most useful for coastal areas under the direct influence of river runoff.

Another sensitivity analysis was carried out by calculating the TRIX from simulated data using $U_{i}$ and $L_{i}$ scaling parameters from three more recent time series with a different temporal length in years: 1991-2010 (model TRIX 1), 20012010 (model TRIX 2), and 2001-2006 (model TRIX 3) (see Table 2). The sensitivity of the TRIX to the three different sets of scaling values was estimated by computing the percentage difference (PD) between the model TRIX 1, 2, and 3 and the model TRIX obtained using the 1983-1992 data series:

$\mathrm{PD}_{i}=\frac{\left(\mathrm{TRIX}_{i}-\mathrm{TRIX}_{83-92}\right)}{\text { TRIX }_{83-92}}$, where $i=1,2,3$. The PD values are shown in Fig. 7 and illustrate the impact on the TRIX values of the time series extension and specific period chosen for the scaling parameters. A shorter time series ( 5 and 10 years) results in $\sim 10 \%$ differences between estimates. Conversely the model TRIX 1 computed with scaling parameters originating from a 20-year time series shows values close to the model TRIX values calibrated with in situ data (Fig. 7).

The correlation between the in situ TRIX and the TRIX calculated from model simulations (model TRIX and model TRIX 1, 2, and 3) varied depending on the time period considered (Table 3). Generally, area A was the best-fitted area, with high correlation values for all the time periods studied. Correlation values decreased in areas $\mathrm{B}$ and $\mathrm{C}$ when we considered short-time-period data (5-10 years). However a high correlation was observed, in all the three areas, between the in situ TRIX and the model TRIX 1 calculated using $U_{i}$ and $L_{i}$ values from a long time series (20 years) (Table 3 ).

The results of the sensitivity analysis, focused on the assessment of the model capability to provide a useful TRIX index, suggest the use of simulated time series of at least 10 years to obtain the upper and lower limits for the state variables involved in the TRIX computation.

In all cases, model values are better correlated with in situ ones in eutrophic as compared to quasi-oligotrophic areas and in nearshore than offshore areas. 

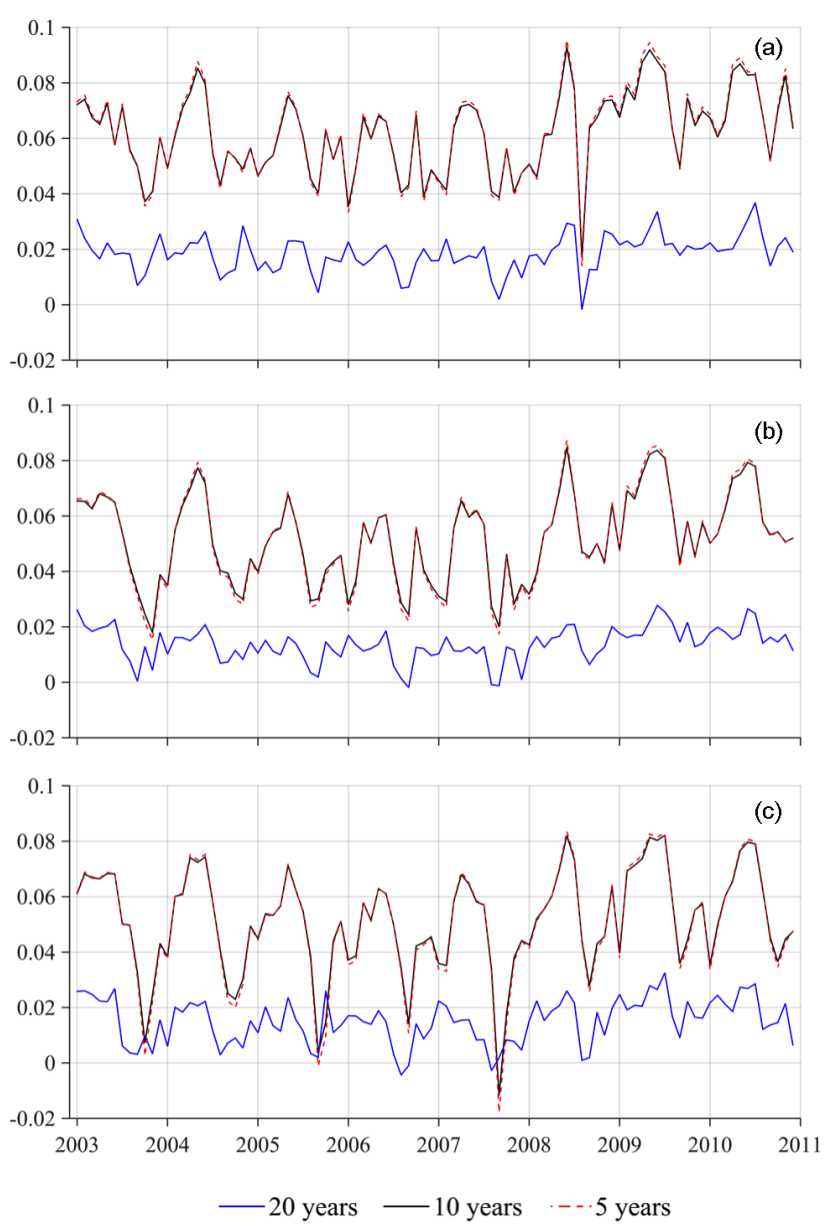

Figure 7. Fraction differences between the TRIX calculated from simulated data using $U_{i}$ and $L_{i}$ values from three recent time series: 20-year (1991-2010, model TRIX 1), 10-year (2001-2010, model TRIX 2), and 5-year (1991-1995, model TRIX 3) data series; and the model TRIX calculated using $U_{i}$ and $L_{i}$ from the 1983-1992 data series. Values are averaged over the three areas (A, B, and C).

\section{Adriatic Sea model TRIX}

Finally, the model TRIX was computed for the whole Adriatic and Northern Ionian Sea. The monthly means computed for the time period 2001-2010 are shown in Fig. 8.

There is a sharp contrast between the coastal northwestern shores, the southeastern shelves, and the open-sea areas. The northwestern Adriatic Sea shows the highest TRIX values ( $>6$ ), corresponding to eutrophic conditions that could be related to possible anoxia/hypoxia events. The TRIX values progressively decrease along the western Adriatic coast, with values ranging between 5 and 6 on the Emilia-Romagna coast and values $<5$ along the Marche coast. The southern section of the western Adriatic presents low TRIX values $(<4)$, as opposed to the southeastern shelves, where eutrophic conditions are prevalent as found in previous studies (Marini et al., 2010). The northern Ionian Sea is generally oligotrophic, with TRIX values $<4$.

\section{Discussion and conclusion}

In this paper we have adapted the TRIX generic equation to an ecosystem model simulation, and we have computed the TRIX over an entire sea basin region. In order to calibrate the model index, all the index scaling parameters were calculated from the model simulation itself. Each state variable is scaled by the highest $\left(U_{i}\right)$ and the lowest $\left(L_{i}\right)$ values in the data time series, and in our paper we tested the importance of the length and the specific period used to evaluate these scaling parameters.

The analysis was based on a comparison of in-situ-dataderived TRIX and the model TRIX on the Emilia-Romagna coastal strip. First of all, the results indicated the generally significant potential skill of the model in replicating the observed index, provided that the TRIX scaling parameters are computed from the simulated data set itself. The comparison also indicated that in a statistical sense the model's replication skill decreases consistently with the trophic characteristics' tendency towards oligotrophic conditions. This is indicated by the decreasing correlation values from area A to areas $\mathrm{B}$ and $\mathrm{C}$. This obviously merits further investigation as it is probably related to the main driver controlling the local environmental conditions (external input vs. circulation and vertical structure dynamics).

Despite the good correlation between model and in situ TRIX values, it is clear that the model obtains such values with different proportions of the four state variables, Chl, DO, DIN, and TP. In particular we observed that the model generally underestimates the total phosphorous and overestimates the dissolved oxygen. This model-data discrepancy leads to a general underestimation of the model efficiency coefficient with respect to the in situ data. However, both the model results and the in situ data showed that the efficiency coefficient is low, $-2 /-2.5$, implying high nutrient utilization, which can be related to the potential productivity of the system, in agreement with Giovanardi and Vollenweider (2004).

The sensitivity analysis to the extension and specific time series used to evaluate the scaling parameters indicated that for time series longer than 10 years the results were insensitive to the $\left(U_{i}\right)$ and $\left(L_{i}\right)$ values. This is because a long data series is more likely to encompass a wide range of events and better estimate extremes.

When implemented in the whole Adriatic Sea basin scale, the model TRIX produced the sharp transition from the eutrophic oriented conditions of the coastal domain, to the oligotrophic conditions that characterize the pelagic domain.

Numerical simulations can therefore represent an important support for monitoring activities; i.e., they will allow the use of TRIX to be extended to much larger areas where in 

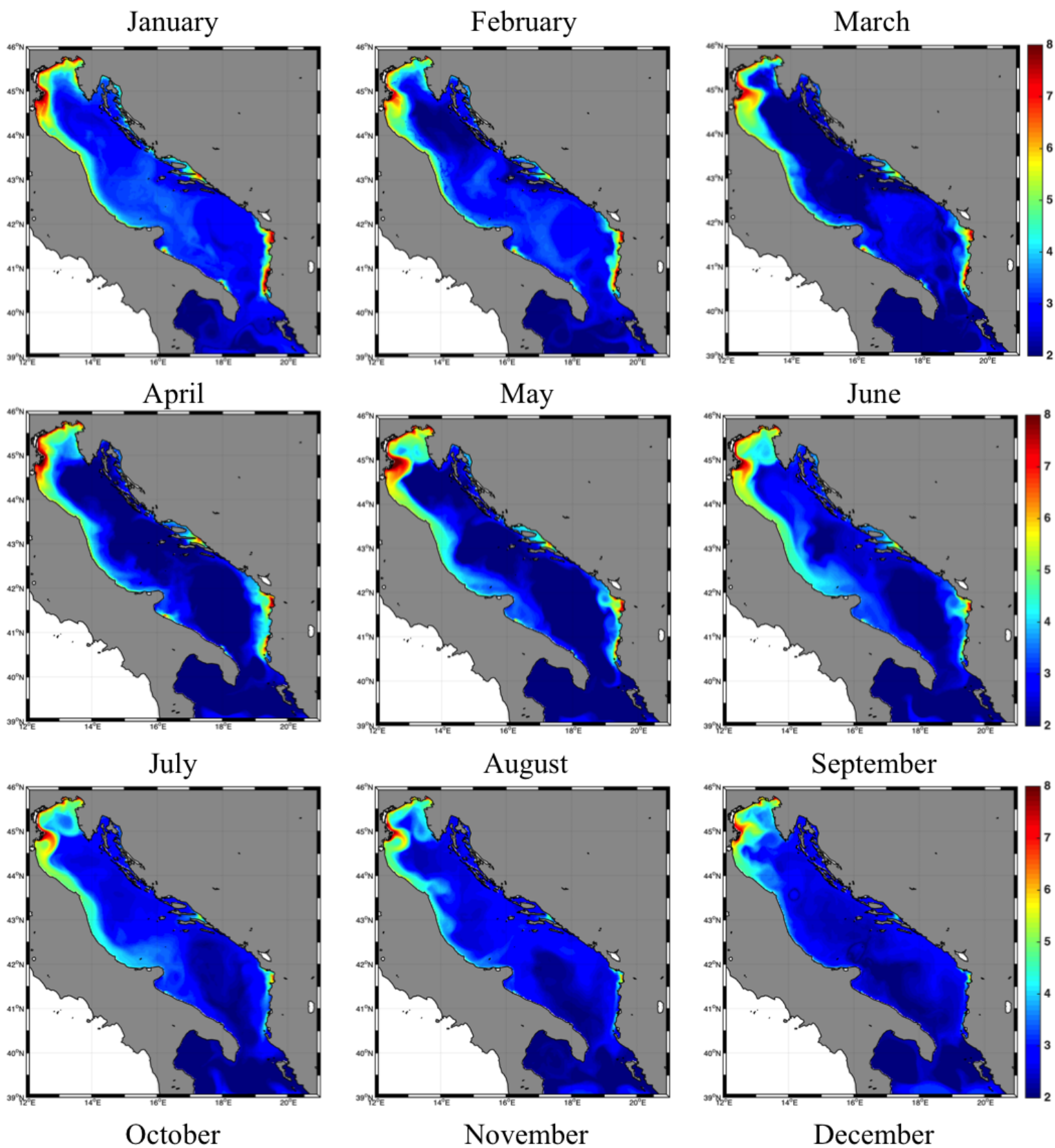

October
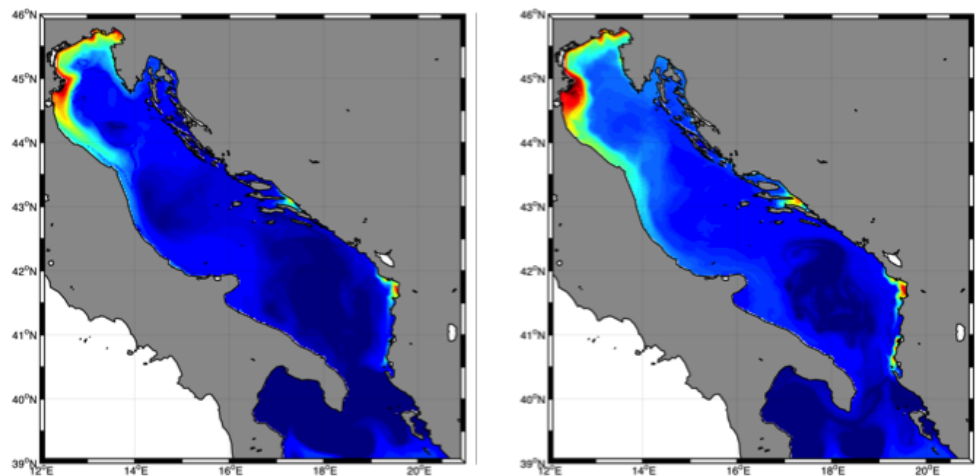

December

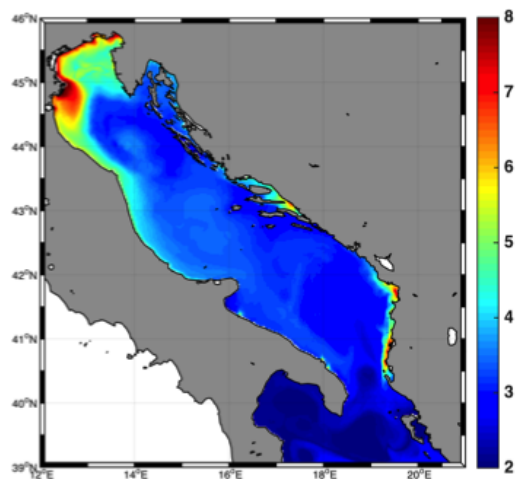

Figure 8. Monthly averages of the model TRIX for the Adriatic and upper Ionian Sea. 
situ sampling activities are difficult to implement. However it is important to realize that in the future it will be desirable to use several numerical models instead of just one realization in order to associate model uncertainties with the model TRIX estimates.

\section{Data availability}

The data sets on the simulated trophic index (TRIX) and the four state variables comprising the index (chlorophyll $a$, oxygen, dissolved inorganic nitrogen, and total phosphorous) are available upon request to L. Giacomelli (l.giacomelli@unibo.it). The data set on in situ data is available upon request to Agenzia Regionale Prevenzione Ambiente Energia (ARPAE) dell'Emilia-Romagna, Struttura Oceanografica Daphne (daphne@arpa.emr.it).

Acknowledgements. This research received partial support from the PON (Programma Operativo Nazionale) project "TESSA" (Tecnologie per la Cognizione dell'Ambiente a Mare), funded by the Italian Ministry of Education and of Economic Development, and by the EU FP7 project "PERSEUS" (Policy-Oriented marine Environmental Research for the Southern European Seas).

Edited by: R. Archetti

Reviewed by: two anonymous referees

\section{References}

Balkis, N., Toklu-Alicli, B., and Balci, M.: Evaluation of ecological quality status with the trophic index (TRIX) values in the coastal waters of the Gulfs of Erdek and Bandirma in the Marmara Sea, in: Ecologiacal Water Quality - Water Treatment and Reuse, edited by: Voudouris, K., doi:10.5772/1070, 2012.

Baytut, O., Gonulol, A., and Koray, T.: Temporal variation of phytoplankton in relation to eutrophication in Samsun Bay, Southern Black Sea, Turk. J. Fish. Aquat. Sc., 10, 363-372, 2010.

Blumberg, A. F. and Mellor, G. L.: A description of a threedimensional coastal ocean circulation model, in: Three dimensional coastal ocean model, edited by: Heaps, N. S., Am. Geophys. Union, 1987.

Clementi, E., Zavatarelli, M., and Oddo, P.: Simulating the interannual variability of the Adriatic Sea ecosystem dynamics, Rapp. Comm. Int. Mer Médit., 39, p. 325, 2010.

Dyatlov, S. E., Nikulin, V. V., Petrosyan, A. G., Koshelev, O., and Bogatova, Y.: Ecological and toxicological monitoring results of Chanem Danube-Black Sea in 2008, Scientific proceedings of Ternopol National University, Hydroecology, 3, 82-85, 2010.

Ferreira, J. G., Andersen, H. J., Borja, A., Bricker, S. B., Camp, J., Cardoso da Silva, M., Graces, E., Heiskanen, A. S., Humborg, C., Ignatiades, L., Lancelot, C., Menesguen, A., Tett, P., and Hoepffner, N.: Overview of eutrophication indicators to assess environmental status within the European Marine Strategy Framework Directive, Estuar. Coas. Shelf Sc., 93, 117-131, 2011.
Giovanardi, F. and Vollenweider, R. A.: Trophic conditions of marine coastal waters: experience in applying the Trophic Index TRIX to two areas of the Adriatic and Tyrrhenian seas, J. Limnol., 2, 199-218, 2004

Kovalova, N. and Medinets, V.: Comprehensive assessment of longterm changes of the Black Sea surface waters quality in the Zmiinyi Island area, Turk. J. Fish. Aquat. Sc., 12, 485-491, 2012.

Marini, M., Grilli, F., Guarnieri, A., Jones, B. H., Klajic, Z., Pinardi, N., and Sanxhaku, M.: Is the southeastern Adriatic Sea coastal strip an eutrophic area?, Estuar. Coast. Shelf S., 88, 395-406, doi:10.1016/j.ecss.2010.04.020, 2010.

Medinets, V., Kovalova, N., Snigirov, S., and Gruzova, I.: Assessment of marine water quality in the Zmiinyi Island area using TRIX index, Scientific Proceedings of Ternopol National University, Hydrology, 3, 159-162, 2010.

Moncheva, S. and Doncheva, V.: Eutrophication index ((E) TRIX) an operational tool for the Black Sea coastal water ecological quality assessment and monitoring, International Symposium "The Black Sea Ecological Problems" (SCSEIO), Odessa, 178$185,2000$.

Moncheva, S., Doncheva, V., Shtereva, G., Kamburska, L., Malej, A., and Garinstein, S.: Application of eutrophication indices for assessment of the Bulgarian Black Sea coastal ecosystem ecological quality, Water Sci. Technol. 46, 19-28, 2002.

Montanari, G., Rinaldi, A., Pinardi, N., Simoncelli, S., and Giacomelli, L.: The currents of Emilia-Romagna coastal strip during the period 1995-2002, I quaderni di ARPA 2006, ARPA Agenzia Regionale Prevenzione e Ambiente dell'Emilia-Romagna, 2006.

Regione Emilia-Romagna: Eutrofizzazione delle acque costiere dell'Emilia-Romagna, rapport annuali, A cura di: Arpa Struttura Oceanografica Daphne, Pubbl. Assessorato Agricoltura, Ambiente e Sviluppo Sostenibile, Bologna, 1981-2013.

Rinaldi, A. and Giovanardi, F.: Contribution of Richard A. Vollenweider toward understanding eutrophication of the coastal Adriatic Sea, Aquat. Ecosyst. Health Manag., 14, 200-203, 2011.

Salas, F., Teixeria, H., Marcos, C., Marques, J. C., and PérezRuzafa, A.: Applicability of the trophic index TRIX in two transitional ecosystems: the Mar Menor lagoon (Spain) and the Mondego estuary (Portugal), International Council for the Exploration of the Sea, ICES J. Mar. Sci., 65, 1442-1448, 2008.

Shahrban, M. and Etemad-Shahidi, A.: Classification of the Caspian Sea coastal waters based on trophic index and numerical analysis, Environ. Monit. Assess., 164, 349-356, doi:10.1007/s10661009-0897-6, 2010.

Tugrul, S., Uysal, Z., Erdogan, E., and Yucel, N.: Kilikya Baseni (Kuzeydogu Akdeniz) sularinda otrofikasyon indicatoru parametrelerin (TP, DIN, Chl- $a$ ve TRIX) degisimi, Ekoloji, 20, 33-41, 2011.

Vaschetta, M., Kauppila, P., and Furman, E.: Aggregate indicators in coastal policy making: Potentials of the trophic index TRIX for sustainable considerations of eutrophication, Sustain. Dev., 16, 282-289, 2008.

Vichi, M., Pinardi, N., and Masina, S.: A generalized model of pelagic biogeochemistry for the global ocean ecosystem, Part I: Theory, J. Mar. Systems, 64, 89-109, 2007.

Vollenweider, R. A., Rinaldi, A., and Montanari, G.: Eutrophication, structure and dynamics of a marine coastal system: results of ten years monitoring along the Emilia-Romagna coast (Northwest Adriatic Sea), in: Marine Coastal Eutrophication, edited by: 
Vollenweider, R. A., Marchetti, R., and Viviani, R., Elsevier, Amsterdam, 63-106, 1992.

Vollenweider, R. A., Giovanardi, F., Montanari, G., and Rinaldi, A.: Characterization of the trophic conditions of the marine coastal waters with special reference to the NW Adriatic Sea: proposal for a trophic scale, turbidity and generalized water quality index, Environmetrics, 9, 329-357, 1998.

Yucel-Gier, G., Pazi, I., Kucuksezgin, F., and Kocak, F.: The composite trophic status index (TRIX) as a potential tool for regulation of Turkish marine aquaculture as applied to the eastern Agean coast (Izmir Bay), Appl. Ichthyol, 27, 39-45, 2011.
Zaika, V. Y.: On the trophic status of pelagic ecosystems in different Black Sea regions, Marine Ecol., 1, 5-10, 2003.

Zoriasatein, N., Jalili, S., and Poor, F.: Eavaluation of ecological quality status with the Trophic Index (TRIX) values in coastal area of Arvand, northeastern of Persian Gulf, Iran, World J. Fish Mar. Sci., 5, 257-262, 2013. 